\title{
Quality evaluation of iron-containing food supplements in the Palestinian market
}

\author{
Murad ABUALHASAN ${ }^{1 *}$ (D), Shorouq DWAIKAT ${ }^{1}$, Rawan ATAYA ${ }^{1}$, Anagheem ALI ${ }^{1}$, and Munir AL-ATRASH ${ }^{2}$
}

\begin{abstract}
Iron is widely used to treat anemia and is prescribed or sold as an over-the-counter drug and food supplement in the local market as well as community pharmacy. The iron supplements available in the Palestinian market were tested for their claimed iron content (\% assay) and microbial contamination. Altogether, 18 samples of different pharmaceutical dosage forms were collected from the Palestinian market. These samples represented both local and international markets. The actual iron content in the sample products was determined using potentiometric titration and atomic absorption methods. Moreover, bacterial and fungal contaminations were tested according to international pharmacopeial methods. Results revealed that $72 \%$ of the tested samples failed the test, and most of them exceeded the standard limit. The results varied according to source and dosage form. This shows that the iron supplements in the Palestinian markets do not meet the international standard allowable limits. Responsible authorities must take an urgent action. In particular, the Ministry of Health should take corrective actions, such as monitoring the registration and performing regular quality checks on imported and local products.
\end{abstract}

Keywords: iron; food supplement; quality.

Practical Application: The study showed the importance of implementing continuous quality control of iron containing food supplement sold in community pharmacies and supermarkets. The results showed that many of the sold brand do not comply with the set international standard which may cause health hazards.

\section{Background}

Iron is an essential metal for many human body functions, including hemoglobin formation, brain development and function, body temperature regulation, muscle activity, and catecholamine metabolism (Lieu et al., 2001). The major role of iron in hemoglobin is to distribute oxygen to different body tissues and cells. Approximately $60 \%-70 \%$ of iron in the human body circulates in the blood as hemoglobin (Kohgo et al., 2008; Park, 2015). The rest are stored in the form of ferritin and hemosiderin in the liver, spleen, marrow, duodenum, skeletal muscle, and other anatomic areas (Saito, 2014).

The median dietary intake of iron is approximately $16-18 \mathrm{mg} /$ day for men and $12 \mathrm{mg} /$ day for women (Institute of and Panel on 2002, Rajbhandari, Aryal et al. 2013). Nutritional iron-deficiency anemia is the most common form of anemia, which arises when the physiological needs are unmet by iron absorption from natural sources (Zimmermann \& Hurrell, 2007). The World Health Organization defines anemia as a drop in blood hemoglobin levels to below $13 \mathrm{~g} / \mathrm{dL}$ in men and $12 \mathrm{~g} / \mathrm{dL}$ in women (Johnson-Wimbley \& Graham 2011).

Oral iron supplements are the first preferred treatment for anemia and thus are frequently prescribed and sold as over-thecounter (OTC) drugs to the public.

Various dosage forms of iron are available worldwide, as well as in Palestinian pharmacies and hospitals. These dosage forms include tablets, caplets, soft and hard gelatin capsules,

oral drops, and solutions for intravenous injection. These forms contain iron in different salts: sulfate, gluconate, fumarate, and bisglycinate (Institute of Medicine, 2002).

Pharmaceutical preparations containing iron are registered either as food supplements or drugs depending on the iron content in the dosage form (United States Pharmacopeial, 2010).

Many studies worldwide have shown that the claimed compositions of many dietary supplements in the market were different from the actual quantities when tested via different analytical techniques. The products that do not meet the preset registration quality standards could lead to toxicity and severe side effects (Gurley et al., 2000, Opperman et al., 2011, LeDoux et al., 2015, Andrews et al., 2016, Andrews et al., 2018).

Many iron-containing pharmaceutical preparations in the Palestinian market are either locally manufactured or imported through registered drugstores. These preparations contain iron in different amounts, either alone or in combination with other active ingredients, such as folic acid, vitamins, and minerals.

In Palestine, the Ministry of Health $(\mathrm{MOH})$, through its registration department, directorate of pharmacy, is responsible for the registration of food supplements, which represent approximately $11 \%$ of all pharmaceutical products (Palestinian Ministry Of Health). Registering drugs involve well-defined rules. However, the registration requirements for food supplements 
are newly established, and the rules set are still unsatisfactorily implemented (Abualhasan et al., 2019), (Palestinian Ministry of Health, 2020).

In this study, we aimed to evaluate iron-containing drugs and food supplements in the Palestinian market and provide appropriate recommendations to the responsible authorities. In addition, we aimed to create suitable awareness programs for all concerned parties, including $\mathrm{MOH}$, community pharmacies, and the public, regarding the hazards of administering substandard pharmaceuticals and food supplements. Various methods are available for iron analysis. In this study, potentiometric titration and atomic absorption spectroscopy were chosen to accurately quantify the iron content of the samples.

\section{Methods}

\subsection{Materials and reagents}

All chemicals used in this study were purchased from reliable sources. Cerium sulfate (Sigma-Aldrich, UK), sulfuric acid ( $\mathrm{H}_{2} \mathrm{SO}_{4} ; 95 \%-97 \%$; Merck, Germany), ACS grade hydrochloric acid, (HCl; 36.5\%-38.0\%; Alfa Aesar, USA), and dichloromethane (Sigma-Aldrich, UK) were used. Tryptic Soy Agar (Difco " ${ }^{\mathrm{Nm}}$; France), Sabouraud Dextrose Agar (Difco ${ }^{\mathrm{m}}$; France) were used in media preparation, Tryptic Soy Broth (Difco ${ }^{\mathrm{Tm}}$; France), Tween 80 (Difco ${ }^{\mathrm{mw}}$; France) were used in Fluid 3 preparationand were used in the microbiological testing. All the tested tablets, syrups, hard and soft gelatin capsules were purchased from local community pharmacies in Palestine.

\subsection{Instrumentation}

An intelligent ultrasonic processor (UCD-1200, Biobase, China) was used to dissolve the samples for potentiometric titration. A hotplate (LMS-1003, LabTech, Italy) was used to stir the samples during the titration and digestion for atomic absorption. A pH potentiometer (3510, Jenway, UK) was used to read the potential. Autoclave (Model DLOV 3764; DE-Lama) was used in sterilization of fluid 3 (F3) and Ager. Laminar Air Flow (BBS-V1300; Biobase), Incubators (BC3100-R1; Biorold) were used in microbiological testing of samples, and a Vortex (Genie 2 SI) was used for sample mixing.

\subsection{Analytical procedure}

\subsubsection{Sample preparation}

Samples for potentiometric analysis: An average weight of the sample powder was added to $5 \mathrm{~mL}$ of $\mathrm{H}_{2} \mathrm{SO}_{4}(98 \%)$, and $100 \mathrm{~mL}$ of distilled water was added to the mixture. Subsequently, the mixture was placed in a sonicator to ensure complete dissolution of the sample.

Samples for atomic absorption analysis: A sample powder was accurately weighed and added to $20 \mathrm{~mL}$ of $32 \%(\mathrm{v} / \mathrm{v}) \mathrm{HCl}$. Approximately $10 \mathrm{~mL}$ of water was added, and the resulting sample mixture was stirred for 20-30 min. The solution was filtered and then diluted with distilled water to $100 \mathrm{~mL}$ in a volumetric flask. Serial sample dilutions (3-9 ppm) were prepared.
Preparation of soft gelatin capsules: Five soft gelatin capsules were dissolved in $20 \mathrm{~mL}$ dichloromethane. The solution was then extracted three times with $20 \mathrm{~mL}$ water each time using a separatory funnel.

\subsubsection{Potentiometric analysis of iron samples:}

Preparation of the primary standard cerium sulfate solution: A standard cerium sulfate solution $(0.1 \mathrm{M})$ was prepared by dissolving $33.276 \mathrm{~g}$ of cerium sulfate with $1 \mathrm{M} \mathrm{H}_{2} \mathrm{SO}_{4}$ in a $1 \mathrm{~L}$ volumetric flask. Subsequently, $250 \mathrm{~mL}$ of the prepared solution was diluted to $500 \mathrm{~mL}$ to obtain a molarity of $0.05 \mathrm{M}$.

Standardization of the cerium sulfate solution: Ammonium iron (II) sulfate hexahydrate $(784.26 \mathrm{mg})$ was dissolved in $100 \mathrm{~mL}$ distilled water and titrated with the prepared cerium sulfate solution. Subsequently, the accurate molarity of the cerium sulfate solution was determined.

Potentiometric titration of the iron samples: The prepared sample solution was placed in a conical flask. The potentiometer electrodes were immersed in the sample solution. A standardized cerium sulfate solution from the burette was gradually added to a conical flask containing the sample. After every addition of cerium sulfate solution, the potential reading $(\mathrm{mV})$ was recorded. The end point was determined from the recorded middle of the inflection point of the generated curve.

Calculation of iron content of the samples: The volume of cerium sulfate solution in the $\mathrm{x}$-axis was plotted against the potential in the $y$-axis. The equivalent point was determined and used to calculate the iron content in each tablet or capsule. Titration was performed in triplicate, and the average of three readings was used to calculate the $\%$ assay of iron.

According to the international pharmacopeia, the sample will pass if the analysis result was within the acceptable range. However, if the sample failed the assay test, then the sample was analyzed again via another method. If both analyses gave failed results, then the sample would fail according to the rules of good laboratory practices (GLP) (Cooke \& Furman, 1950).

\subsubsection{Determination of iron content via atomic absorption spectroscopy}

A stock solution $(100 \mathrm{mg} / \mathrm{mL})$ was prepared by dissolving $135.63 \mathrm{mg}$ of ferrous sulfate. Serial dilutions of this stock were prepared with concentrations of $1,2,5,8$, and $10 \mathrm{mg} / \mathrm{mL}$. A standard calibration curve was constructed by plotting the atomic absorption of these solutions against the concentration of the standard solution. The regression equation of the calibration curve was used to calculate the concentration of ferrous ions in the analyzed samples (Allan, 1959).

\subsection{Microbiological contamination}

Microbiological tests were performed according to the specified section $<61>$ of the United States Pharmacopeia USP (United States Pharmacopeial 2004). An aerobic plate count assay was performed to determine whether a product was contaminated with bacteria or fungi. This assay is a quantitative analysis that determines the total aerobic microbial count (TAMC) and total yeast and mold 
count (TYMC) of the sample. In addition, microbiological tests were performed to ensure the absence of certain microorganisms, such as clostridia, salmonellae, and Shigella. The microbial limits stated that the TYMC and TAMC for the tested oral dosage forms should not exceed 100 and 1000 colony-forming units (cfu) per gram respectively (United States Pharmacopeial, 2017).

\subsection{Statistical analysis}

Statistical Package for the Social Sciences (SPSS) software program was used to perform descriptive analysis. Analysis of variance (ANOVA) test was used to test if there was a statistical significant different between means. Pearson's chi-squared test was used to determine whether there is a significant difference between the expected frequencies and the observed frequencies in more than one categories. In all the mentioned statistical test if the p-value is less than 0.05 , the null hypothesis was rejected and it was concluded that a significant difference does exist.

\section{Results}

\subsection{Sample distribution}

A total of 18 samples of different pharmaceutical dosage forms were analyzed. Tablets constituted $44 \%$ of the analyzed samples. Figure 1 illustrates the percentage of each dosage form.

The samples were either locally manufactured or imported. The imported samples accounted for approximately $78 \%$ of the samples. This value reflects the percentage of iron tablets in the community pharmacies (Figure 2).

\subsection{Assay test results}

Figure 3 demonstrates the results of the potentiometric titration and atomic absorption analyses of the samples. Approximately $72 \%$ of the tested samples failed the assay test.

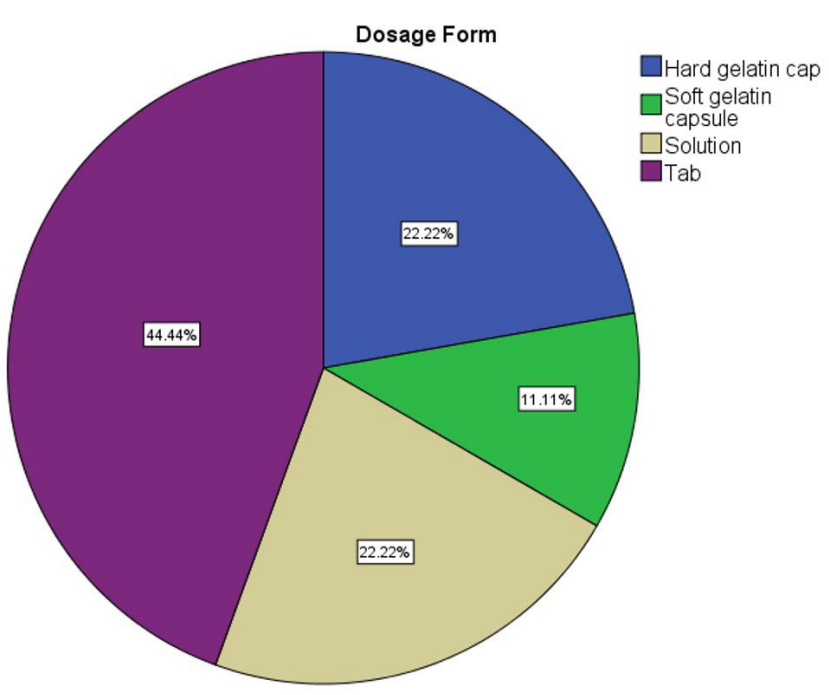

Figure 1. Dosage forms.
The $\%$ assay of the tested samples showed that most of the samples exceeded the permitted pharmacopeial limits. Figure 4 shows that the \% assay curve was skewed to the right. This curve demonstrates that a large number of the results had high \% assay values. Among all the values, the lowest \% assay was $32.46 \%$, whereas the highest was $333.6 \%$.

The result distribution for the tested samples according to dosage form is presented in Table 1 and Figure 5. The results showed that the tablet form had equal number of passes and fails. For the other dosage forms of iron products, the number of failed samples was considerably greater than that of passed samples. To determine whether the results according to product dosage form were statistically different, a chi-square test was performed. The p value was $>0.05$, which indicates that the results based on different dosage form were not statistically different.

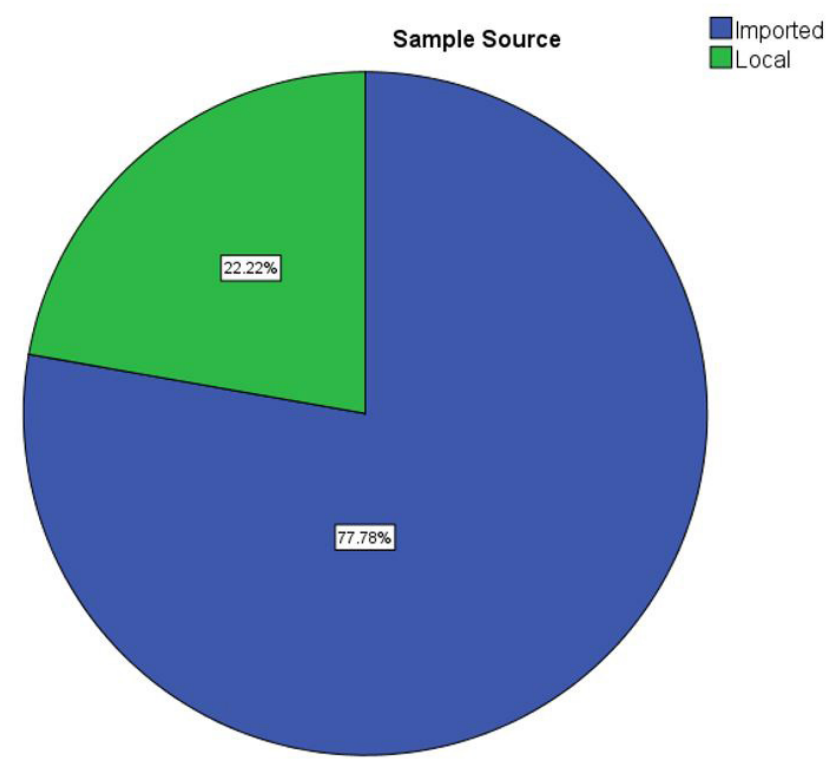

Figure 2. Sample sources.

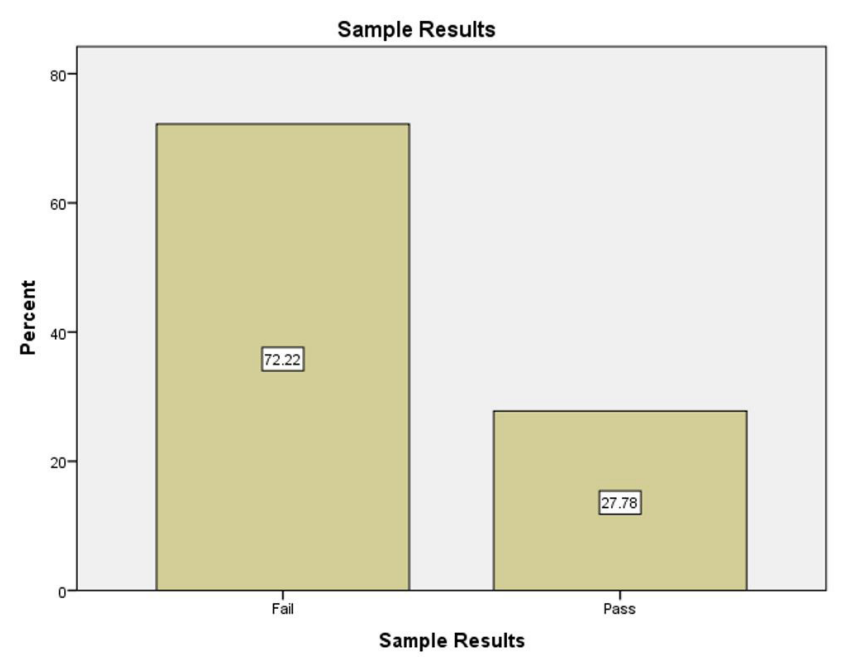

Figure 3. Assay test results. 
The influence of the sample source, whether imported or locally manufactured, on the test results was examined. Based on the data provided in both Table 2, the local samples ( 3 out of 4;

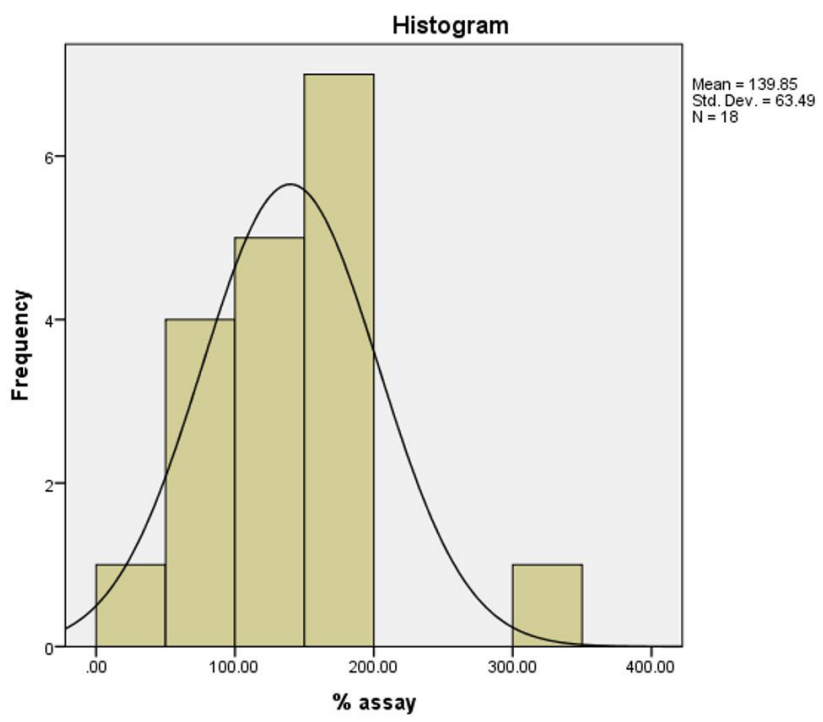

Figure 4. Normal distribution of the $\%$ assay results for the tested samples.

Table 1. Assay results based on dosage form.

\begin{tabular}{llcc}
\hline \multirow{2}{*}{ Dosage form } & \multicolumn{2}{c}{ Results } \\
\cline { 3 - 4 } & Hard gelatin capsule & Fail & Pass \\
\hline & Soft gelatin capsule & 2 & 1 \\
& Solution & 4 & 0 \\
& Tablet & 4 & 0 \\
& & 13 & 4 \\
Total & & & 5 \\
\hline
\end{tabular}

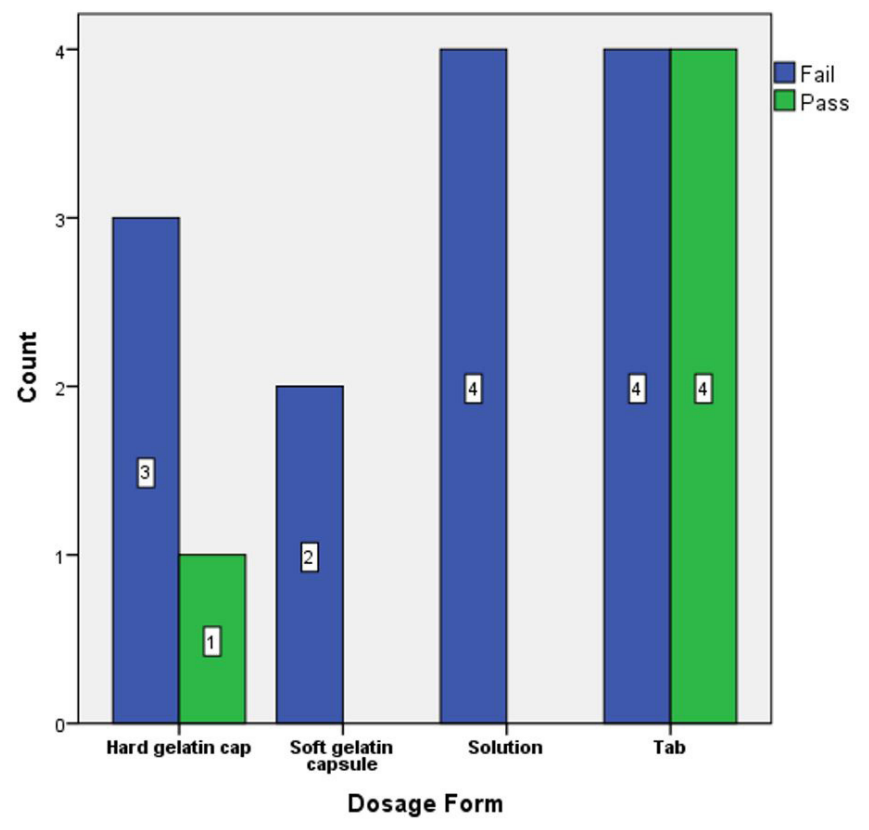

Figure 5. Assay results based on dosage form.
$75 \%$ ) had more pass results than the imported samples ( 2 out 14 or $14.29 \%)$. The result distribution showed that the imported samples had more pass results than the locally manufactured samples. A chi-square test showed that the results for the local and imported samples were statistically different. Interestingly, the $\mathrm{p}$ value was $<0.05$, which proved that the local samples had more failed results than the imported drugs. Moreover, the results were statistically different.

\subsection{Microbiological test results}

The microbial test results for all the samples were within the acceptable limits. In addition, the tested samples did not contain microorganisms, such as clostridia, salmonellae, and Shigella.

\section{Discussion}

The tested samples were of different pharmaceutical dosage forms, including tablets, syrups, and soft and hard gelatin capsules. Tablets are the most sold pharmaceutical dosage by community pharmacies and food supplement sellers in the market (Helliwell \& Taylor 1993). In our study, majority of the analyzed samples were tablets (44\%). Thus, our study had a satisfactory sample dosage form distribution that represents the real market. The tested samples were either locally manufactured or imported. In this study, imported samples constituted approximately $78 \%$ of the total samples. This percentage represents the actual situation of the Palestinian market as the majority of food supplements and drugs are manufactured by multinational companies rather than local companies. Unfortunately, majority of the imported samples are not registered in the Palestinian MOH (Palestinian Ministry of Health 2018). Registration of drugs and food supplements is extremely important and helps to ensure that only good quality pharmaceuticals are distributed in the market.

Many analytical methods can be applied to quantify iron. The state of iron plays an important role in determining a suitable analytical method. In our research, we used potentiometric titration with a suitable oxidizing agent (cerium). For iron samples in ferric form, atomic absorption spectroscopy was used. Both methods are accurate and precise (Wachasunder \& Nafade, 2001; Liang et al., 2018).

Results showed that the majority of the tested samples were above the pharmacopeial allowable limits. This finding remarkably demonstrates that manufacturers generally add iron in amounts that are above the claimed values in the label. In the pharmaceutical industry, using an overage of a drug substance is a common procedure to compensate for the degradation during manufacture or shelf life of a product; in addition, this method is used to extend the shelf life of a product. However, this strategy is discouraged because adding considerably more than the allowable pharmacopeial limit may cause health hazards (Sane et al., 2018; Yuen \& Becker 2020).

Table 2. Assay results according to sample source.

\begin{tabular}{lccc}
\hline \multirow{2}{*}{ Sample Source } & \multicolumn{2}{c}{ Results } \\
\cline { 2 - 4 } & Imported & Fail & Pass \\
\hline \multirow{3}{*}{ Total } & Local & 1 & 2 \\
& & 13 & 3 \\
\end{tabular}




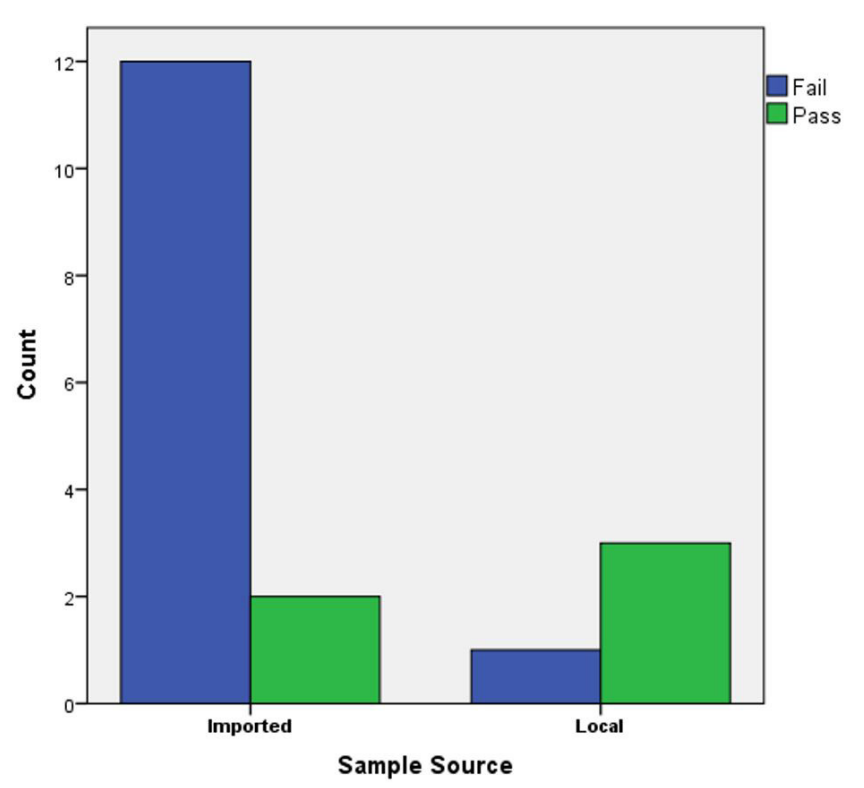

Figure 6. Results according to sample source.

The results in Figure 5 demonstrate that the quality of iron drugs and food supplements was not statistically related to dosage form, thereby emphasizing that the quality, regardless of dosage form, must be regulated by the concerned authorities. Generally, stability is affected by dosage form. Liquids are less stable than tablets (Mollica et al., 1978). However, Figure 6 shows that the results for the imported samples were significantly different from those for the locally manufactured samples. Accordingly, responsible authorities are advised to establish and implement rules, including good manufacturing practices (GMP) and GLP.

The microbiological tests revealed that all the tested samples passed, probably because of appropriate storage conditions. Both iron drugs and food supplements were collected from community pharmacies, where these items are usually stored under suitable storage conditions. In our previous study on herbals, the results showed significant contamination of the tested herbals; this contamination was primarily attributed to improper storage by herbal traditional shops (Abualhasan et al., 2019).

The overall results of this study are important and alarming. The results alarm the $\mathrm{MOH}$ and all concerned parties to take immediate measurements. Corrective actions, such as awareness programs regarding the use of substandard iron drugs, should be conducted for product consumers, such as pregnant women, geriatrics, and children. Regular monitoring of GMP and GLP application in local manufacturing companies must be enforced. Moreover, the $\mathrm{MOH}$ must register all imported iron and other food supplements through licensed drugstores. This step will help prevent the presence of fraud brands and substandard pharmaceuticals in the market.

\section{Conclusion}

Iron supplements are frequently sold over the counter (OTC) and highly consumed by the community. Thus, the $\mathrm{MOH}$ must intensively inspect the quality of these products, which are available in community pharmacies and supermarkets. The majority of the samples failed the assay test, which is alarming. Therefore, an immediate action must be taken, and the $\mathrm{MOH}$ should focus on locally manufactured drugs as they failed more significantly than the imported ones. Moreover, the $\mathrm{MOH}$ must register all imported and locally manufactured brands. Regulatory authorities must perform regular quality control checks regarding iron content and conduct microbiological tests for all iron-containing products in the local market.

\section{References}

Abualhasan, M., Jaradat, N., Sawaftah, Z., Mohsen, H., Najjar, D., \& Zareer, W. (2019). Evaluation of heavy metals and microbiological contamination of selected herbals from Palestine. Open Life Sciences, 14(1), 448453. http://dx.doi.org/10.1515/biol-2019-0050. PMid:33817180.

Allan, J. E. (1959). The determination of iron and manganese by atomic absorption. Spectrochimica Acta, 15, 800-806. http://dx.doi. org/10.1016/S0371-1951(59)80376-3.

Andrews, K. W., Gusev, P. A., McNeal, M., Savarala, S., Dang, P. T. V., Oh, L., Atkinson, R., Pehrsson, P. R., Dwyer, J. T., Saldanha, L. G., Betz, J. M., Costello, R. B., \& Douglass, L. W. (2018). Dietary Supplement Ingredient Database (DSID) and the application of analytically based estimates of ingredient amount to intake calculations. The Journal of Nutrition, 148(Suppl. 2), 1413S-1421S. http://dx.doi.org/10.1093/ jn/nxy092. PMid:31505677.

Andrews, K. W., Roseland, J. M., Gusev, P. A., Palachuvattil, J., Dang, P. T., Savarala, S., Han, F., Pehrsson, P. R., Douglass, L. W., Dwyer, J. T., Betz, J. M., Saldanha, L. G., \& Bailey, R. L. (2016). Analytical ingredient content and variability of adult multivitamin/mineral products: national estimates for the Dietary Supplement Ingredient Database1,2. The American Journal of Clinical Nutrition, 105(2), 526-539. http://dx.doi.org/10.3945/ajcn.116.134544. PMid:27974309.

Cooke, W. D., \& Furman, N. H. (1950). Coulometric titrations with electricity generated ferrous iron. Analytical Chemistry, 22(7), 897899. http://dx.doi.org/10.1021/ac60043a013.

Gurley, B. J., Gardner, S. F., \& Hubbard, M. A. (2000). Content versus label claims in ephedra-containing dietary supplements. American Journal of Health-System Pharmacy, 57(10), 963-969. http://dx.doi. org/10.1093/ajhp/57.10.963. PMid:10832496.

Helliwell, M., \& Taylor, D. (1993). Solid oral dosage forms. Professional Nurse, 8(5), 313-317. PMid:8451252.

Institute of Medicine - US. Panel on Micronutrients. (2002). Dietary reference intakes for vitamin $A$, vitamin $K$, arsenic, boron, chromium, copper, iodine, iron, manganese, molybdenum, nickel, silicon, vanadium, and zinc. Washington, DC: National Academy Press.

Johnson-Wimbley, T. D., \& Graham, D. Y. (2011). Diagnosis and management of iron deficiency anemia in the 21 st century. Therapeutic Advances in Gastroenterology, 4(3), 177-184. http:// dx.doi.org/10.1177/1756283X11398736. PMid:21694802.

Kohgo, Y., Ikuta, K., Ohtake, T., Torimoto, Y., \& Kato, J. (2008). Body iron metabolism and pathophysiology of iron overload. International Journal of Hematology, 88(1), 7-15. http://dx.doi.org/10.1007/ s12185-008-0120-5. PMid:18594779.

LeDoux, M. A., Appelhans, K. R., Braun, L. A., Dziedziczak, D., Jennings, S., Liu, L., Osiecki, H., Wyszumiala, E., \& Griffiths, J. C. (2015). A quality dietary supplement: before you start and after it's marketed--a conference report. European Journal of Nutrition, 54(S1, Suppl. 1), S1-S8. http://dx.doi.org/10.1007/s00394-014-0827-4. PMid:25579377.

Liang, J., Zhu, J., Gong, L., Liu, X., \& Wang, B. (2018). Potentiometric titration for the high precision determination of active components 
in six types of chemical disinfectants. PLoS One, 13(9), e0203558. http://dx.doi.org/10.1371/journal.pone.0203558. PMid:30192844.

Lieu, P. T., Heiskala, M., Peterson, P. A., \& Yang, Y. (2001). The roles of iron in health and disease. Molecular Aspects of Medicine, 22(1-2), 1-87. http://dx.doi.org/10.1016/S0098-2997(00)00006-6. PMid:11207374.

Mollica, J. A., Ahuja, S., \& Cohen, J. (1978). Stability of pharmaceuticals. Journal of Pharmaceutical Sciences, 67(4), 443-465. http://dx.doi. org/10.1002/jps.2600670405. PMid:347049.

Opperman, M., Marais, W., \& Spinnler Benade, A. J. (2011). Analysis of omega-3 fatty acid content of South African fish oil supplements. Cardiovascular Journal of Africa, 22(6), 324-329. http://dx.doi. org/10.5830/CVJA-2010-080. PMid:22159321.

Palestinian Ministry of Health. (2020). Registered Products. from http:// pharmacy.moh.ps/index/RegisteredProducts/Language/en

Palestinian Ministry of Health (2018). Instructions for Registration and Trading of Medicinal Plants and Food Supplements. Palestine: Ministry of Health.

Park, K. (2015). Park's textbook of preventive and social medicine. India: Bhanot Publishers.

Rajbhandari, A., Aryal, A., \& Rajbhandari, S. D. (2013). Determination of iron in iron tablets by spectrophotometry and atomic absorption spectroscopy. International Journal of Pharmaceutical and Biological Archives, 4(3), 435-438.

Saito, H. (2014). Metabolism of iron stores. Nagoya Journal of Medical Science, 76(3-4), 235-254. PMid:25741033.
Sane, M. R., Malukani, K., Kulkarni, R., \& Varun, A. (2018). Fatal iron toxicity in an adult: clinical profile and review. Indian Journal of Critical Care Medicine: Peer-Reviewed, Official Publication of Indian Society of Critical Care Medicine, 22(11), 801-803. http://dx.doi.org/10.4103/ijccm.IJCCM_188_18. PMid:30598567.

United States Pharmacopeial (2004). General Chapter 61. Microbial Limit Tests (USP 27-NF 22, pp. 2152-2157). Rockville, MD: US Pharmacopeial Convention.

United States Pharmacopeial (2010). USP 33; NF 28: The national formulary; NF 28 reissue: new and revised official text since the second supplement to USP 32-NF 27. Rockville, MD: United States Pharmacopeial Convention.

United States Pharmacopeial (2017). The United States Pharmacopeia 2018: USP 41; The national formulary: NF 36. Rockville, MD: United States Pharmacopeial Convention.

Wachasunder, S. D., \& Nafade, A. (2001). Precision and accuracy control in the determination of heavy metals by atomic absorption spectrometry. The International Journal of Environmental Studies, 58(4), 517-528. http://dx.doi.org/10.1080/00207230108711348.

Yuen, H. W. and W. Becker (2020). Iron Toxicity. Treasure Island, FL: StatPearls Publishing.

Zimmermann, M. B., \& Hurrell, R. F. (2007). Nutritional iron deficiency. Lancet, 370(9586), 511-520. http://dx.doi.org/10.1016/S01406736(07)61235-5. PMid:17693180. 